\begin{tabular}{lc}
\hline \hline UNDERGROUND MINING ENGINEERING 37 (2020) 51-59 & UDK 62 \\
UNIVERSITY OF BELGRADE - FACULTY OF MINING AND GEOLOGY & ISSN 03542904 \\
\hline \hline & \\
& Original scientific paper
\end{tabular}

\title{
APPLICATION OF ESP PUMP WITH INTELLIGENT CONTROL SYSTEM IN WELL $X$
}

\author{
Irina Zahirović ${ }^{1}$, Dušan Danilović², Bojan Martinović1
}

Received: December 3, 2020

Accepted: December 17, 2020

\begin{abstract}
ESP (Electric Submersible Pump) pumps are one of many methods of artificial lift used in the world. By optimizing the operation of the pump, a balance is achieved between the inflow of fluid from the reservoir and the equipment, which prolongs the run life of the equipment and increases production. Remote monitoring of the ESP system and its parameters in real time enables the evaluation of the pump's performance trend, as well as the prediction of potential equipment failure, which leaves room to take measures that would prevent well workover. The level of technology, in addition to monitoring, also offers remote and automatic control of the ESP system. Intelligent control stations of the ESP system use mathematical algorithms to draw and analyze the pump performance curve and, based on them, automatically change their operating parameters so that they are the most optimal. Another great advantage of this system is that it allows virtual measurement of well production via an algorithm based on IPR (Inflow Performance Relationship) analysis.
\end{abstract}

Keywords: ESP pump, intelligent control system

\section{INTRODUCTION}

In today's world, keeping up with technology development is essential for all types of businesses. Digital transformation, the fourth industrial revolution, seeks to completely change the way processes work within a company. In this way, companies improve their business by increasing the efficiency of various procedures by processing large amounts of data faster and more accurately using artificial intelligence and machine learning. As the time goes, companies will become less and less dependent on the human factor. Processes that save a considerable amount of time, technologies that enable remote management, reduction and smarter use of labor, easier consumer targeting, market

${ }^{1}$ NIS Gazprom Neft

${ }^{2}$ University of Belgrade - Faculty of Mining and Geology

E-mails: irina.zahirovic@nis.eu; dusan.danilovic@rgf.bg.ac.rs; bojan.martinovic@nis.eu; 
needs forecasting, not only connecting but also communicating different processes and learning from it, are some of the benefits of digital transformation.

Digital transformation is gaining momentum in the oil industry as well, given that there is a huge space for reorganization of the work process and obtaining economic benefits. ESP pumps with intelligent control system are one of the processes that have undergone digital transformation within the oil industry.

Oil and gas wells in Serbia includes ESP pumps as artificial lift method. Almost all wells are covered with automated metering device. The scope of this paper was to explain novel approach in monitoring and optimization of the wells with ESP pumps.

\section{INFLOW PERFORMANCE RELATIONSHIP}

IPR curves enable the understanding of the relationship between the amount of fluid produced and bottom hole flowing pressure(Golan et al,1995). They were developed with the aim of optimizing production, proper planning of the production system and selection of artificial lift methods (Takacs, 2009).

Many methods have been developed to determine the characteristics of fluid inflow into the well, but Vogel's method is the only one that can be used to determine the IPR curve when one set of data is available (Danilovic et al, 2015). In 1968, Vogel developed a method for calculating the IPR curve on the example of a reservoir with a solution-gas drive (Soleša et al,1999). Based on research that included oils of different viscosities and GOR, different values of relative permeability, various spacing between wells and different types of porosity (primary and secondary), he concluded that when the diagram shows bottom hole well pressure as a fractional part of reservoir pressure in relation to the production shown as a fractional part of the maximum possible production - for all examined cases almost the same shape of the curve is obtained and this curve is called the dimensionless IPR curve (Vogel, 1968). Based on the dimensionless IPR curve, an empirical relationship (Eq.1) was obtained (Vogel, 1968):

$$
\frac{q_{o}}{\left(q_{o}\right)_{\max }}=1-0.2 \frac{P_{w f}}{P_{R}}-0.8\left(\frac{P_{w f}}{P_{R}}\right)^{2}
$$

where:

$\mathrm{q}_{\mathrm{o}}$ - producing rate corresponding to a given well intake pressure [BOPD],

$\mathrm{q}_{\mathrm{o}}(\max )$ - maximum producing rate $[\mathrm{BOPD}]$,

$\mathrm{P}_{\mathrm{wf}}$ - well intake pressure [psi],

$\mathrm{P}_{\mathrm{R}}-$ reservoir pressure $[\mathrm{psi}]$. 
To estimate the amount of fluid produced, the intelligent control station of the ESP system uses the Vogel method to determine the characteristics of fluid inflow into the well (Bikmukhametov, 2020). When a single measurement of the dynamic bottom hole pressure and corresponding production, the composition of the fluid as well as the value of the reservoir pressure are known, the intelligent station of the ESP draws the corresponding IPR curve by the Vogel method. The dynamic bottom hole pressure is calculated via the intake pressure sensor of the ESP pump and the current production from the IPR curve is determined.

\section{INTELLIGENT CONTROL STATION OF ESP SYSTEM}

For years, the technology of monitoring the operating parameters of the ESP system in real time has been widely applied. The SCADA (Supervisory Control and Data Acquisition) system is connected to the control station on the well and it enables monitoring and analysis of the pump operation at any time from a remote location (Haberer et al, 2014). By monitoring parameters, some of which are temperature, intake pressure and changes in engine load, in real time, it is possible to notice emerging problems, predict equipment failure and apply the necessary actions to prevent this from happening (Brahmantiyo, 2015).

A certain degree of automation of the production process implies that the control station of the ESP system has set certain protections such as:

- Protection for current imbalance

- Over voltage protection and

- Under voltage protection

which leads to the pump shutdown when the defined criteria for a certain protection are reached, which prevents further damage to the equipment.

Although all this has led to drastically less reaction time and reduced the number of severe equipment damage, there is still a certain period of time in which the problem is registered by the dispatcher and engineer, then the decision on the best solution has to be made and after that the operator has to physically go to the well and change the operating parameters of the pump. This period in some cases, and depending on the distance of the well, may be quite sufficient for the pump to fail. In addition to the fact that the process requires some time, there is also a risk of making the wrong decision. By applying intelligent control stations, this problem is solved.

The intelligent control station applies a mathematical model that describes the operation of the reservoir-well-equipment system so that it is in balance, and Figure 1. shows the well scheme and its basic elements that were taken into account when forming the model (Volovodov, 2015). 


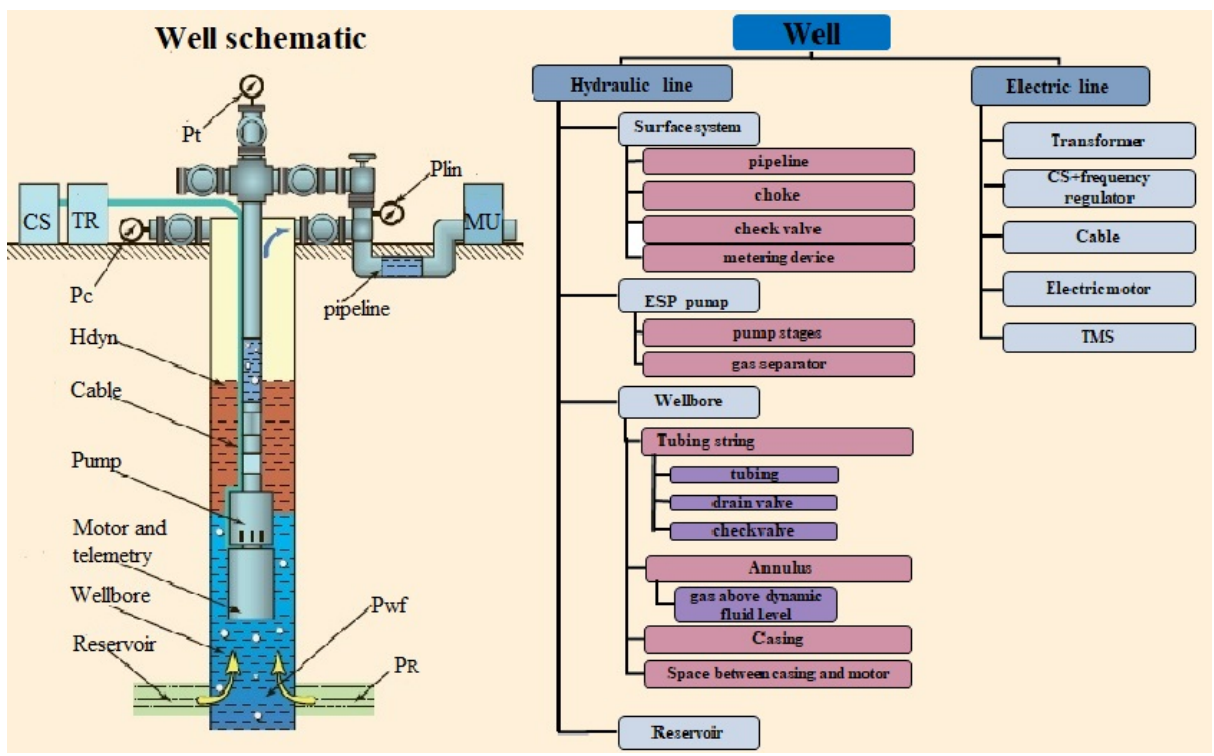

Figure 1 Well model (adapted from Volovodov, 2015)

The benefits of implementing this software solution are reflected in:

- Reducing the number of overload related equipment failures due to optimization of operating parameters based on the dynamic fluid level and production,

- Production increase,

- Flow rate estimation,

- Estimation and optimization of specific energy consumption in different operating conditions,

- Optimal dosage of chemical reagents against scale and paraffin,

- Reducing the number of well visits by operators and engineers,

- Reducing the number of manpower needed to monitor the well fund, leaving engineers more time for specific tasks.

The developed mathematical algorithm has a working principle similar to equipment design software. It is necessary to enter the input data on the characteristics of the reservoir and the production fluid, the well completion and the equipment. The program itself calculates the pump performance curve. Depending on the zone in which the pump is currently operating, the intelligent control station will change the frequency itself in order to achieve the most optimal production conditions. There is no need for the operator to come to the well to manually change the frequency. For better and more 
accurate operation of the station, it is possible to periodically, once in two weeks or once a month, check the parameters that affect the pump performance curve and correct them if necessary.

Flow rate estimation is particularly significant in the cases of (Ivanovskiy et al, 2016):

- New and remote wells that do not have infrastructure,

- Multiple wells feeding into the same pipeline,

- Large number of wells connected to the same automatic metering device and their measuring time is limited,

- Wells operating in an intermittent production mode.

It is also important to mention the cases when the well is not connected to the automatic metering device at all, when the portable three phase measuring separator is often not available and when there are poor access roads to the well.

The production estimation is calibrated to the measurements of the automatic metering device, and the estimated amount of fluid in both ways showed in practice a minimal mutual deviation of 4-5\% (Ivanovskiy et al, 2016).

\section{APPLICATION OF INTELLIGENT CONTROL STATION OF THE ESP SYSTEM ON WELL $X$}

The intelligent control station of the ESP system was applied to well $\mathrm{X}$ as a pilot project. The well was drilled only a few months ago and has not yet been connected to an automatic metering device. In addition, it is remote and the access roads to it are not completely adequate. As the well is new, and the production is worse than expected, constant monitoring is necessary. Production is periodically measured with the help of a portable three phase measuring separator, but since its use is also needed on other wells, it cannot be kept on one well for a longer period of time. The type of pump that is installed is 30-1900 at a depth of $1973 \mathrm{~m}$ and it works in a constant mode. The daily production of the well is $32 \mathrm{~m} 3$ with $95 \%$ water, which is $1.4 \mathrm{t}$ of oil per day.

In order to make a comparison before and after the application of the intelligent control station and to obtain the input parameters for the station, the well operation was monitored for 6 consecutive days before starting the station testing and the operational parameters are given in Table 1. 
Zahirović I., Danilović D., Martinović N.

Table 1 Well X operational parameters before intelligent control station application

\begin{tabular}{lllllll}
\hline Date & $\mathbf{3 1 . 5}$ & $\mathbf{1 . 6 .}$ & $\mathbf{2 . 6 .}$ & $\mathbf{3 . 6}$ & $\mathbf{4 . 6 .}$ & $\mathbf{5 . 6 .}$ \\
$\begin{array}{l}\text { Q fluid, measured [m3/day] } \\
\text { Q fluid, calculated [m3/day] }\end{array}$ & 32,0 & 32,0 & 32,0 & 31,0 & 32,0 & 31,0 \\
$\begin{array}{l}\text { Electric energy consumption, } \\
\text { sensor [kWh/t] }\end{array}$ & 13,7 & 13,5 & 14,0 & 13,0 & 13,5 & 13,7 \\
$\begin{array}{l}\text { Electric energy consumption, } \\
\text { calculated [kWh/t] }\end{array}$ & $/$ & $/$ & $/$ & $/$ & $/$ & $/$ \\
$\begin{array}{l}\text { Fluid level, TMS [m] } \\
\text { Fluid level, calculated [m] }\end{array}$ & 580,0 & 600,0 & 610,0 & 600,0 & 607,0 & 605 \\
$\begin{array}{l}\text { Pin [bar] } \\
\text { Frequency [Hz] }\end{array}$ & 133,0 & 132,0 & 132,0 & 132,0 & 132,0 & 132,0 \\
I [A] & 30,0 & 30,0 & 30,0 & 30,0 & 30,0 & 30,0 \\
\hline
\end{tabular}

After that, a new control station was installed and the operation of the well was monitored for 11 days. Operating mode changes were made step by step:

1. Increasing the frequency in increments of $2 \mathrm{~Hz}$ to $34 \mathrm{~Hz}$ and

2. Stabilization in one mode for 4 days and

3. Frequency reduction in increments of $1 \mathrm{~Hz}$ to $30 \mathrm{~Hz}$.

During the testing period (June 12), the wrong input data for the estimation of the Vogel's IPR curve was entered, which significantly reduced the potential of the well and the estimated production was less than actual. The next day, that error was corrected. Table 2. And Table 3. shows the operational parameters of the well after the installation of the intelligent control station, and Figure 2. shows the well's production profile.

\begin{tabular}{lllllll}
\hline \multicolumn{6}{l}{ Table 2 Well X operational parameters after intelligent control station application } \\
\hline Date & $\mathbf{0 6 . 0 6}$ & $\mathbf{0 7 . 0 6}$ & $\mathbf{0 8 . 0 6}$ & $\mathbf{0 9 . 0 6}$ & $\mathbf{1 0 . 0 6 .}$ & $\mathbf{1 1 . 0 6 .}$ \\
Q fluid, measured [m3/day] & 31,5 & 34,0 & 36,0 & 36,0 & 39,0 & 39,0 \\
Q fluid, calculated [m3/day] & 31,5 & 33,8 & 36,9 & 36,9 & 38,5 & 38,5 \\
$\begin{array}{l}\text { Electric energy consumption, } \\
\text { sensor [kWh/t] }\end{array}$ & 13,7 & 14,1 & 13,7 & 13,7 & 14,1 & 14,2 \\
$\begin{array}{l}\text { Electric energy consumption, } \\
\text { calculated [kWh/t] }\end{array}$ & 13 & 13,3 & 13,7 & 13,3 & 13,4 & 14 \\
$\begin{array}{l}\text { Fluid level, TMS [m] } \\
\text { Fluid level, calculated [m] }\end{array}$ & 570 & 600 & 611 & 610 & 605 & 603 \\
Pin [bar] & 131,0 & 130,0 & 129,0 & 129,0 & 130,0 & 130,0 \\
Frequency [Hz] & 30,0 & $\mathbf{3 2 , 0}$ & $\mathbf{3 4 , 0}$ & 34,0 & 34,0 & 34,0 \\
I [A] & 24,5 & 24,5 & 24,5 & 24,5 & 24,5 & 24,5 \\
\hline
\end{tabular}


Table 3 Well X operational parameters after intelligent control station application

\begin{tabular}{llllll}
\hline Date & $\mathbf{1 2 . 0 6}$. & $\mathbf{1 3 . 0 6}$. & $\mathbf{1 4 . 0 6}$ & $\mathbf{1 5 . 0 6 .}$ & $\mathbf{1 6 . 0 6 .}$ \\
$\begin{array}{l}\text { Q fluid, measured [m3/day] } \\
\text { Q fluid, calculated [m3/day] }\end{array}$ & 37,0 & 37,0 & 35,0 & 34,0 & 31,0 \\
$\begin{array}{l}\text { Electric energy } \\
\text { sensor [kWh/t] }\end{array}$ & 28,9 & 36,0 & 34,0 & 33,0 & 31,4 \\
$\begin{array}{l}\text { Electric energy } \\
\text { calculated [kWh/t] }\end{array}$ & 13,9 & 12,9 & 12,9 & 12,9 & 13,6 \\
$\begin{array}{l}\text { Fluid level, TMS [m] } \\
\text { Fluid level, calculated [m] }\end{array}$ & 13,4 & 13 & 13,5 & 13,2 & 13,8 \\
$\begin{array}{l}\text { Pin [bar] } \\
\text { Frequency [Hz] }\end{array}$ & 602 & 601 & 590 & 590 & 580 \\
I [A] & 131,0 & 131,0 & 132,0 & 133,0 & 133,0 \\
\hline
\end{tabular}

Based on the testing period under different operating conditions, a high degree of correlation of calculated and measured parameters such as production, specific electricity consumption and dynamic fluid level can be noticed, which proves the applicability of this solution. However, it was noticed that the technology is very sensitive to human error, so that the incorrectly entered parameter led to a significant error in the estimation.

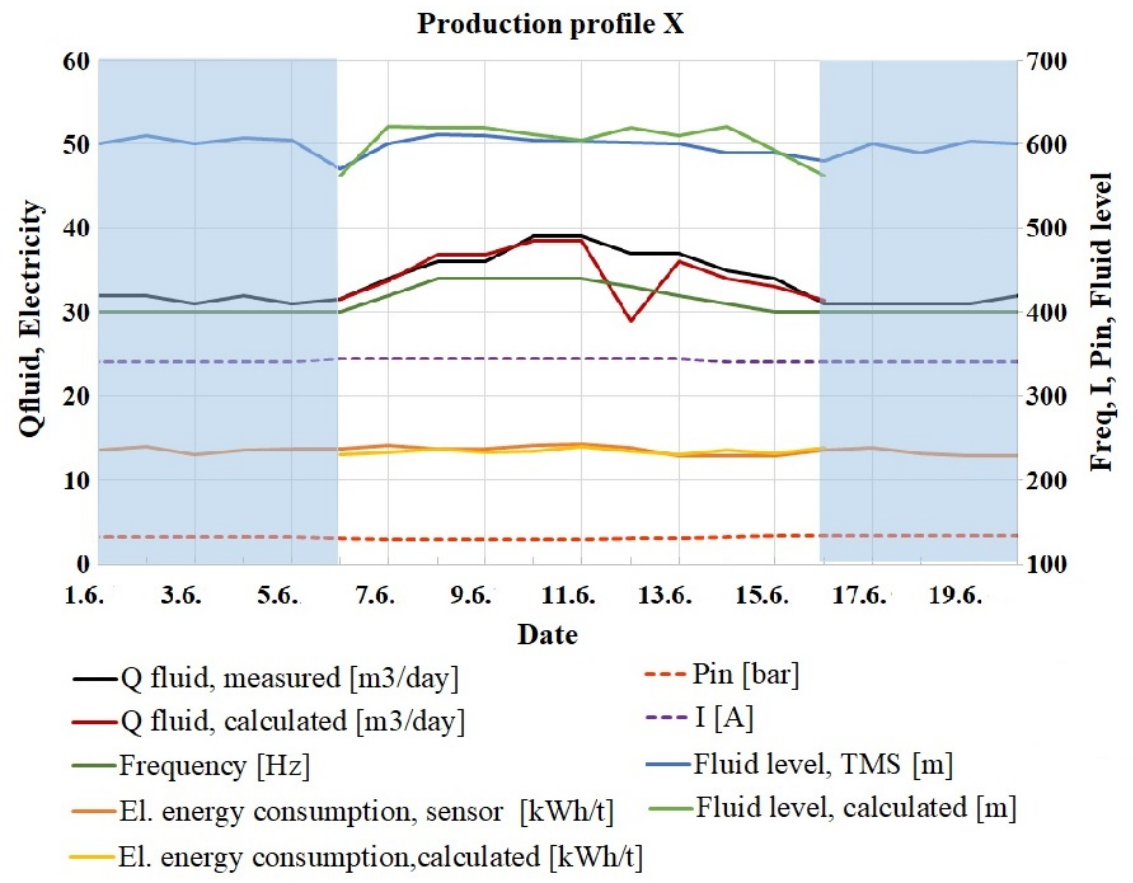

Figure 2 Well production profile 
Zahirović I., Danilović D., Martinović N.

\section{CONCLUSION}

Digital transformation is largely present in the oil industry. The implementation of "smart" technologies enables the shortening of the time of various processes, automatic and remote control, reduces the risk of making wrong decisions and uses people more efficiently, which together leads to improvements in the economic efficiency of the company.

Intelligent control stations of the ESP system, in addition to standard functions such as monitoring and analyzing the operation of the pump at any time from a remote location, raise the level of automation to the next level and enable:

- estimation of parameters such as production, specific energy consumption and dynamic fluid level and

- automatic change of pump operating parameters so as to achieve the most optimal mode

which leads to a reduction in the number of equipment failures due to optimization of parameters and prevention of overload, production increase, reduces the number of well visits, less probability of water coning, sand production decrease, smarter organization of people involved in the process and solves the problem of large infrastructure investments.

The application of the intelligent control station on well $\mathrm{X}$ showed a high degree of correlation of measured and estimated parameters, which proved its efficiency and proposed implementation on other wells in this field.

\section{REFERENCES}

BIKMUKHAMETOV, T. and JÄSCHKE, J. (2020), First Principles and Machine Learning Virtual Flow Metering: A Literature Review, Journal of Petroleum Science and Engineering, 184, 106487.

BRAHMANTIYO, A.S. (2015), North Kuwait ESP Real Time Monitoring: A Study Case for Raudhatain Field, In: Proceedings of the SPE Kuwait Oil and Gas Show and Conference, 11-14 October, Mishref, Kuwait

DANILOVIĆ, D. et al. (2016), Parametri koji definišu optimalnu proizvodnju naftnih bušotina pri primeni mehaničke metode eksploatacije, Tehnika, 71(2), pp. 209-214.

GOLAN, M. and WHITSON, C.H. (1995), Well Performance Second edition, Norwegian University of science and Technology

HABERER, S., KRASIKOV, A. and LAVRINENKO, A. (2014), ESP Monitoring and Control System Implementation in Western Siberia Brownfield, In: Proceedings of the SPE Russian Oil and Gas Exploration \& Production Technical Conference and Exhibition, 14-16 October, Moscow, Russia 
IVANOVSKIY, V.N. et al. (2016), Development And Implementation Of A Virtual Flow Meter For Wells Equipped With Centrifugal Pumps Installations, Territorija “NEFTEGAS” [Oil and Gas Territory], (11):115-120

SOLEŠA, M., DANILOVIĆ, D. and BUZA, Z. (1999), Sistem analiza proizvodnje nafte i gasa eruptivnom metodom, DIT Naftagas

TAKACS, G. (2009), Electrical Submersible Pumps Manual, Gulf Professional Publishing

VOGEL, J.V. (1968), Inflow Performance Relationships for Solution-Gas Drive Wells, Journal of Petroleum Technology, 20(1), pp. 83-92.

VOLOVODOV, A.V. (2015), Интеллектуальный мониторинг и управление скважинными насосными системами, Инженерная практика, по. 09/2015TURIAN, R. M. and YUAN, T. F. (1977) Flow of slurries in pipelines. AICHE Journal, 23 (3), pp. 232-243. https://doi.org/10.1002/aic.690230305

ZANDI, I. (1971) Hydraulic transport of bulky materials. In: Advances in solid-liquid flow in pipes and its applications. Oxford: Pergamon Press.

ZOUAOUI, S. et al. (2016) Experimental study on the effects of big particles physical characteristics on the hydraulic transport inside a horizontal pipe. Chinese Journal of Chemical Engineering, 24 (2), pp. 317-322. https://doi.org/10.1016/j.cjche.2015.12.007 